\title{
A ciência e a RBCE em tempos de pandemia
}

\author{
Fernando Mascarenhas $^{\mathrm{a}}{ }^{\oplus}$, Ari Lazzarotti Filho ${ }^{\mathrm{b}} \odot$, Lauro Casqueiro Vianna $^{\mathrm{C}}{ }^{\oplus}$
}

Ao tempo que lançamos o volume 42 da Revista Brasileira de Ciências do Esporte, enfrentamos uma pandemia. Na véspera de 2020, em 31 de dezembro de 2019, a China alertou Organização Mundial da Saúde (OMS) sobre vários casos de pneumonia na cidade de Wuhan. Uma semana depois, as autoridades chinesas confirmaram que haviam identificado um novo tipo de coronavírus, posteriormente nomeado de SARS-CoV-2, responsável por causar a doença Covid-19. No fim de janeiro, o surto da doença já havia se espalhado constituindo uma emergência internacional e em 11 de março de 2020, a Covid-19 foi caracterizada pela OMS como uma pandemia (OMS, 2020).

Entre o último lançamento e a publicação deste novo volume que abre a parceria com o SciELO, pouco mais de três meses se passaram, tempo mais do que suficiente para vivermos dias que estão mudando o mundo. A estratégia de isolamento social recomendada pela OMS e adotada por vários países para desacelerar a curva de contaminação pelo novo coronavírus criou uma espécie de tempo suspenso, uma emergência que paralisou diversos setores da economia e atingiu em cheio o coração da forma do consumismo que domina nos países ricos.

Segundo dados da OMS (2020), pelo menos 2,8 bilhões de pessoas - mais de um terço da população mundial - vivem atualmente sob alguma restrição de circulação para conter o rápido avanço da Covid-19.

Com a economia em crise, além de políticas emergenciais capazes de mitigar os efeitos da epidemia sobre as parcelas mais pobres das nossas populações, fica evidente a importância de sistemas de proteção social em todo o mundo. A pandemia atinge a todos, mas com maior impacto sobre os mais vulneráveis, tanto no que toca aos aspectos de saúde, como em relação às condições objetivas para o afastamento e isolamento social.

Quanto à estratégia de isolamento social, ela pode dar tempo para que governos se preparem, buscando fortalecer seus sistemas de saúde. Mas o que já se percebe é que diante da pressão econômica e negacionismo, governos vão retirando restrições e flexibilizando quarentenas. De toda forma, teremos de aprender a conviver com o coronavírus e, em maior ou menor grau, medidas de distanciamento social tendem a continuar como um dos elementos dessa nova realidade.

Por sua vez, a emergência na saúde pública evidenciou ainda mais a importância da ciência e das universidades como instituições profundamente envolvidas e essenciais na busca de soluções e realizações de combate à pandemia. Mas o fato é que a pandemia do novo coronavírus chegou ao Brasil em meio a um cenário de cortes no financiamento à pesquisa e desmoralização das universidades, comprometendo a capacidade de resposta do país à Covid-19.

Em 2019, a Academia Brasileira de Ciências $(A B C)$ e outras entidades já alertavam que os cortes no orçamento destinado à Ciência, Tecnologia e Inovação no país significavam

\footnotetext{
a Universidade de Brasília, Faculdade de Educação Física, Brasília, DF, Brasil.

b Universidade Federal de Goiás, Faculdade de Educação Física e Dança, Goiás, GO, Brasil.

c Universidade de Brasília, Faculdade de Educação Física, Brasília, DF, Brasil.
}

\footnotetext{
*Autor correspondente:

Fernando Mascarenhas

E-mail: fernandom@unb.br
} 
um retrocesso ao nível de investimento de 15 anos atrás, prejudicando a qualidade de vida da população brasileira, comprometendo o desenvolvimento, a segurança e a soberania nacionais ( $A B C$ et al., 2019). E se a Comissão de Financiamento à Pesquisa e de Política Científica da SBPC dizia que tínhamos chegado ao fundo do poço (Jornal da Ciência, 2019), novos cortes no número de bolsas e no volume de recursos para financiamento de projetos de pesquisa em 2020 deixaram a comunidade acadêmica perplexa. O que está em curso é a desorganização da ciência. A política do governo Bolsonaro para o desenvolvimento do setor foi concebida com base na premissa de que o fomento à ciência tem de trazer retorno imediato em termos econômicos, desconhecendo a importância dessa área para a formulação de políticas públicas em matéria de ensino, saúde, infraestrutura e saneamento (Jornal da Ciência, 2020).

Enfim, vivemos hoje um clima de desinformação que favorece a disseminação de negacionismos, encampados por governos com políticas escancaradamente anticientíficas. O obscurantismo não só busca desmoralizar retoricamente as universidades e a produção científica, como influi diretamente no corte de verbas e sucateamento da infraestrutura de pesquisa no país. No entanto, no contexto de pandemia, a comunidade científica tem se colocado na linha de frente do real combate à Covid-19, com centenas de ações de enfrentamento realizadas pelas universidades: sequenciamento genético do vírus, produção de equipamentos especializados, produção de testes, pesquisas de medicamentos, desenvolvimento de vacina, etc. (MEC, 2020). O trabalho de cientistas das mais diferentes áreas e de diversos países tem constituído uma rede sólida de informações, colocando a ciência no centro do debate acerca das decisões governamentais.

Neste cenário, compartilhar conhecimento o mais rápido possível e, assim, contribuir com o enfrentamento da crise pandêmica é urgente e necessário. Esta necessidade tem movimentado o mercado editorial científico, com plataformas liberando acesso a artigos e publicando material ainda não revisado para agilizar compartilhamento de dados. O SciELO, por exemplo, deu início à operação do servidor SciELO Preprints - https:// preprints.scielo.org - com o objetivo de acelerar a disponibilização de artigos de pesquisas e outras comunicações científicas antes ou em paralelo à sua avaliação. Embora aberto a todas as áreas temáticas, de imediato servirá às comunicações relacionadas à Covid-19. Através do portal SciELO em Perspectiva se pode ver reunidos em uma coleção um sem número de artigos publicados em diversos periódicos, que expressam a resposta da ciência e das universidades - https://blog.scielo.org/.

Conforme alertamos em volume anterior, a RBCE também foi impactada pelo corte no financiamento da ciência frente à escassez de recursos e editais de apoio à publicação de periódicos por parte das agências de fomento (Mascarenhas et al., 2019a). Com efeito, os desafios impostos pela crise do financiamento público da ciência e pesquisa no país acabou precipitando mudanças em nossa Revista, em grande medida, desencadeadas pela nova parceria firmada com o SciELO (Mascarenhas et al., 2019b).

Inaugurada esta parceria, um novo sistema de submissão foi implantado. A transição do sistema Evise, da Elsevier, para o sistema SciELO ScholarOne implicou numa série de ações e procedimentos técnicos recém-concluídos que possibilitaram a abertura do sistema para novas submissões, já sob novas normas e instruções para os autores, para os quais chamamos atenção (RBCE, 2020). Outra novidade é que a RBCE passa a adotar agora a publicação em fluxo contínuo de artigos, sem a necessidade de esperar a composição completa dos números trimestrais. Essa modalidade promove rapidez no processo de comunicação e disponibilização das pesquisas com inúmeras vantagens para os usuários.

O objetivo principal é acelerar o processo de comunicação das pesquisas e assim contribuir para a sua disponibilidade para leituras e citações. Isto, pois, a legitimidade e desempenho de um periódico científico, para além da tradição e representatividade que este constrói, junto a uma determinada comunidade ou área acadêmica, em grande medida é definida pelo tempo de avaliação dos manuscritos (Mascarenhas et al., 2019c).

Nessa linha, podemos apresentar alguns números que indicam a evolução da RBCE em 2019: 


\begin{tabular}{|c|c|c|c|}
\hline Artigos & 1은 Semestre & 2ㅇ Semestre & Total Anual \\
\hline a) Recebidos: & 133 & 124 & 257 \\
\hline b) Aprovados (independente de quando foram originalmente submetidos): & 17 & 16 & 33 \\
\hline $\begin{array}{l}\text { c) Rejeitados (número total, independente de quando foram originalmente } \\
\text { submetidos): }\end{array}$ & 52 & 47 & 99 \\
\hline $\begin{array}{l}\text { d) Dentre os Rejeitados (item c), número de rejeitados na primeira análise pela } \\
\text { equipe técnica, editor-chefe ou editor associado, ou seja, não seguiram para a } \\
\text { avaliação por pares ou outro tipo de avaliação que o periódico utiliza: }\end{array}$ & 21 & 17 & 38 \\
\hline $\begin{array}{l}\text { e) Tempo médio (em dias) de avaliação dos manuscritos aprovados e rejeitados } \\
\text { (não incluem os rejeitados no recebimento, informados no item d): }\end{array}$ & 84 & 108,7 & $104,9 *$ \\
\hline
\end{tabular}

Segundo o SciELO (2014), o tempo médio de avaliação dos manuscritos deve ser de até 6 meses, considerando o tempo entre as datas de submissão e de decisão final quanto à publicação. No geral, em 2019, a RBCE levou pouco mais de 3 meses para processar a avaliação dos artigos contra os 7 meses verificados em 2018. Além de conseguir maximizar a eficiência do processo de avaliação da RBCE, minimizando o tempo entre a submissão e o parecer final, nosso objetivo ao implantar a publicação em fluxo contínuo de artigos é baixar também o tempo entre a submissão e a publicação do manuscrito.

Com mais agilidade e transparência, seguimos buscando qualificar a RBCE. Nessa direção, provocados pela própria crise e em resposta ao que a ciência deve produzir, estamos trabalhando na implantação da RBCE Preprints, com o objetivo de acelerar a disponibilização de artigos de pesquisas e outras comunicações científicas antes ou em paralelo à sua avaliação. Tal qual o SciELO, de imediato, servirá às comunicações relacionadas com a Covid-19.

Quanto a este volume 42 da RBCE, serão pelo menos 60 artigos publicados no ano, confirmando o caráter interdisciplinar e plural da Revista.

Boa leitura! Brasília, abril de 2020.

\section{REFERÊNCIAS}

Academia Brasileira de Ciências ( $A B C$ ), Associação Nacional dos Dirigentes de Instituições Federais de Ensino (Andifes), Conselho Nacional das Fundações de Amparo à Pesquisa (Confap), Conselho Nacional de Secretários Estaduais para Assuntos de Ciência e Tecnologia (Consecti), Fórum Nacional de Secretários Municipais da Área de Ciência e Tecnologia, Sociedade Brasileira para o
Progresso da Ciência (SBPC). Corte orçamentário atinge desenvolvimento e soberania nacionais [Internet]. Brasília (DF): ABC; 2019; [acesso em 2020 abr 10]. Disponível em: http://jcnoticias.jornaldaciencia.org.br/wp-content/ uploads/2019/04/Of.-SBPC-035-manifesto-conjunto_corteor\%C3\%A7ament\%C3\%A1rio-2019.pdf

Mascarenhas F, Lazzarotti Filho A, Vianna LC. Crise no financiamento à pesquisa e desafios para RBCE. Rev Bras Ciênc Esporte. 2019a;41(3):231-2.

Mascarenhas F, Lazzarotti Filho A, Vianna LC. RBCE, mais um ciclo se encerrando e novos desafios. Rev Bras Ciênc Esporte. 2019b;41(4):341-2.

Mascarenhas F, Lazzarotti Filho A, Vianna LC. Revista Brasileira de Ciências do Esporte diminui seu tempo médio de processamento. Rev Bras Ciênc Esporte. 2019c;41(1):1-2.

Mazza M. Comissão da SBPC faz balanço das ações estratégicas para o financiamento do setor. Jornal da Ciência [Internet]. 2019; [acesso em 2020 abr 10]. Disponível em: http://www. jornaldaciencia.org.br/comissao-da-sbpc-faz-balanco-dasacoes-estrategicas-para-o-financiamento-do-setor/

Ministério da Educação (MEC). Coronavírus: monitoramento nas instituições de ensino [Internet]. Brasília (DF): MEC; 2020; [acesso em 2020 abr 10]. Disponível em: http:// portal.mec.gov.br/coronavirus/

Organização Mundial da Saúde (OMS). Discurso de abertura do Diretor-Geral da OMS no briefing da mídia sobre COVID-19 - 11 de março de 2020 [Internet]. Genebra: OMS; 2020; [acesso em 2020 abr 10]. Disponível em: https:// https:// www.who.int/dg/speeches/detail/who-director-generals-opening-remarks-at-the-media-briefing-on-covid-19-11march-2020.

Revista Brasileira de Ciências do Esporte (RBCE). Instruções aos autores [Internet]. Brasília (DF): RBCE; 2020; [acesso em 2020 abr 10]. Disponível em: http://www.scielo.br/ revistas/rbce/pinstruc.htm

Scientific Electronic Library Online (SciELO). Critérios, política e procedimentos para a admissão e a permanência de periódicos científicos na Coleção SciELO Brasil. São Paulo (SP): SciELO; 2014; [acesso em 2020 abr 10]. Disponível em: http://www.scielo.br/avaliacao/20141003NovosCriterios_ SciELO_Brasil.pdf

Sociedade Brasileira para o Progresso da Ciência (SBPC). A desorganização da ciência [Internet]. São Paulo (SP): SBCP; 2020; [acesso em 2020 abr 10]. Disponível em: http://portal. sbpcnet.org.br/noticias/a-desorganizacao-da-ciencia/ 